\title{
Mechanical and FEA-Assisted Characterization of 3D Printed Continuous Glass Fiber Reinforced Nylon Cellular Structures
}

\author{
Evangelos Giarmas ${ }^{1}$, Konstantinos Tsongas ${ }^{1,2} \mathbb{D}$, Emmanouil K. Tzimtzimis ${ }^{1}$, Apostolos Korlos ${ }^{2} \mathbb{D}$ and \\ Dimitrios Tzetzis $1, *$ (D) \\ 1 Digital Manufacturing and Materials Characterization Laboratory, School of Science and Technology, \\ International Hellenic University, 14 km Thessaloniki, 57001 N. Moudania, Greece; \\ e.giarmas@ihu.edu.gr (E.G.); k.tsongas@ihu.edu.gr (K.T.); m.tzimtzimis@ihu.edu.gr (E.K.T.) \\ 2 Department of Industrial Engineering and Management, School of Engineering, International Hellenic \\ University, 14 km Thessaloniki, 57001 N. Moudania, Greece; apkorlos@ihu.gr \\ * Correspondence: d.tzetzis@ihu.edu.gr
}

check for updates

Citation: Giarmas, E.; Tsongas, K.; Tzimtzimis, E.K.; Korlos, A.; Tzetzis, D. Mechanical and FEA-Assisted Characterization of 3D Printed Continuous Glass Fiber Reinforced Nylon Cellular Structures. J. Compos. Sci. 2021, 5, 313. https:/ / doi.org/10.3390/jcs5120313

Academic Editor: Francesco Tornabene

Received: 3 November 2021 Accepted: 23 November 2021 Published: 27 November 2021

Publisher's Note: MDPI stays neutral with regard to jurisdictional claims in published maps and institutional affiliations.

Copyright: (c) 2021 by the authors. Licensee MDPI, Basel, Switzerland. This article is an open access article distributed under the terms and conditions of the Creative Commons Attribution (CC BY) license (https:/ / creativecommons.org/licenses/by/ $4.0 /)$.

\begin{abstract}
The main objective of this study was to investigate the mechanical behavior of 3D printed fiberglass-reinforced nylon honeycomb structures. A Continuous Fiber Fabrication (CFF) 3D printer was used since it makes it possible to lay continuous strands of fibers inside the 3D printed geometries at selected locations across the width in order to optimize the bending behavior. Nylon and nylon/fiberglass honeycomb structures were tested under a three-point bending regime. The microstructure of the filaments and the 3D printed fractured surfaces following bending tests were examined with Scanning Electron Microscopy (SEM). The modulus of the materials was also evaluated using the nanoindentation technique. The behavior of the 3D printed structures was simulated with a Finite Element Model (FEM). The experimental and simulation results demonstrated that 3D printed continuous fiberglass reinforcement is possible to selectively adjust the bending strength of the honeycombs. When glass fibers are located near the top and bottom faces of honeycombs, the bending strength is maximized.
\end{abstract}

Keywords: additive manufacturing; continuous fiber fabrication (CFF); honeycomb structures; glass fiber; nylon; finite element analysis

\section{Introduction}

Additive Manufacturing (AM), or 3D printing, is widely used for the fabrication of polymer components ranging from prototypes to final products. Various Additive Manufacturing techniques for polymer manufacture have been developed, such as Stereolithography (SLA), Selective Laser Sintering (SLS) and Fused Deposition Modelling (FDM). The latter is the most widely utilized system for polymer AM manufacturing offers relatively low costs, low material consumption and ease of use. However, one of the drawbacks of 3D printing technology has been the low mechanical strength of the raw utilized materials [1-3]. The most common materials limit the use of 3D printing to prototyping and modeling, without being able to produce usable products, as they are weak and brittle. Nowadays, 3D printing materials can be used in many demanding applications and fiber-reinforced 3D printed materials in particular have a promising future [4]. Several research studies have reported 3D printing structures reinforced with different kinds of short fibers or inclusions [5-9]. One of the latest efforts in this direction has been made through the application of Continuous Fiber Fabrication (CFF) 3D printing machines, which lay continuous composite fibers, such as Kevlar and carbon fiber, inside 3D printed thermoplastics to improve their mechanical properties [10-15]. Blok et al. [16] investigated and compared these two different methods of composite 3D printing, continuous fiber printing and short fiber printing, in terms of their mechanical properties, part quality and 3D printing versatility. The tensile strength and stiffness of the continuous fiber printed 
parts were $986 \mathrm{MPa}$ and $64 \mathrm{GPa}$, respectively. A drawback of the continuous fiber printer, however, is limited control over the placement of the fiber and the formation of voids when 3D printing more complex shapes.

Melenka et al. [17] carried out tensile tests on four combinations of Kevlar-reinforced tensile coupons that were built using the MarkOne ${ }^{\mathrm{TM}}$ 3D printer by Markforged. The testing outputs showed that an increase in the volume of fiber reinforcement led to an increase in the ultimate strength and stiffness of the test samples. In another study, the idea of designing the nozzle in a way to uniformly mix the carbon fiber and PLA resin was analyzed [18]. Due to the weak bonding behavior between carbon fiber and PLA resin, the preprocessing of carbon fibers was essential in order to achieve better interfacial strength. The experiments indicated that the modified carbon fiber-reinforced composites demonstrated $164 \%$ and $13.8 \%$ higher flexural strength and tensile strength, respectively, than the original carbon fiber-reinforced samples. In addition, the modified carbon fiber-reinforced samples presented higher storage modulus than the PLA and original fiber-reinforced samples, at about $166 \%$ and $351 \%$, respectively. Furthermore, the results from the Scanning Electron Microscope (SEM) indicated better fiber matrix bonding behavior of the carbon fiber preprocessed printing technology. In order to study how different reinforcements affect energy absorption, Petrone et al. [19] compared two different specimens under low velocity impact loading. The first consisted of polyethylene honeycombs reinforced with continuous-unidirectional fibers and the second consisted of short-random fibers. The presence of face sheets and the influence of core height were investigated for each specimen. The cores made from continuous fiber-reinforced composite, presented a large elastic region and increased peak loads, showing a better response to impact loading compared to the short fiber-reinforced composites. The presence of face sheets enhanced the energy absorption of the panels due to the fact that the energy was dissipated during bending and stretching the face sheets. However, this phenomenon seemed to reduce at larger core heights. This was also supported by statistical analysis based on the Taguchi method, which presents an important antagonistic interaction between the existence of face sheets and the core height. Finally, for high strain rate applications and for large deflections, thermoplastic honeycomb cores reinforced with continuous fibers presented higher peak force transmission.

López et al. [20] evaluated the elastic properties of 3D printed carbon fiber pylon under compression stress and compared them with experimental data, in order to estimate its properties and allow the use of Finite Element Analysis (FEA) tools. The results from the FEA of the 3D printed reinforced material demonstrated a relative error of $16.4 \%$. However, several factors affected the mechanical behavior of the reinforced polymer. These included the width, the distance between extruded filaments, the layer thickness, and the filament pattern. Given such complexity, the relative error obtained was considered acceptable. Further simulations for a prototype were also developed, showing that the prototype exceeded the yield point at $42.03 \mathrm{MPa}$.

Another important difficulty in the process of simulating 3D printed materials in FEA software is the determination of the parameters that may affect the tensile strength of the printed structures. Parameters such as the orientation angle, type of material and infill rate were selected by Heechang et al. [21] in order to estimate which of them affected the mechanical properties of the specimens. An optical microscope was used to test any effects on the extruded filament. The best mechanical properties were found in materials in the x-direction, with fill rates of $100 \%$ (using PLA), and it was also possible to print products with improved mechanical properties using these factors. Considering the fact that PLA and ABS are the most common filaments, experiments in order to verify the difference in tensile strength have been conducted by taking into account the proportion of these materials. However, the results from the Analysis Of Variance (ANOVA) showed the inadequate extrusion of FDM as a 3D printing method. The problem was that potential overlaps and voids may occur in the boundary between two 3D printed materials. To solve such problems, the researchers changed the structural design by adding horizontal layers 
and vertical lines. However, simply adding more vertical lines to the product may still be ineffective, since overlaps and voids may exist between the materials. Nevertheless, an additional horizontal layer improved the mechanical behavior of the part [22].

Honeycomb with hexagonal cells is the most common structure amongst cellular materials and can be easily fabricated using different technologies and materials. However, to meet the specific needs of many applications, hexagonal honeycomb structures evolved into many new forms in the industrial environment, leading to rapidly increasing diversity from traditional engineering to micro- and nano-fabrication [23]. Honeycomb structures make it possible to save materials, as well as reducing the weight and cost of the structures during the design process. Furthermore, honeycomb structures feature relatively high compression and shear properties [24]. Generally, the internal angles of honeycombs are different and do not feature cell walls of equal lengths. In addition, the thickness of the cell walls may not be the same [7]. Honeycomb structures are usually built of sheets or plates that form the edges of unit cells, with their thickness ranging from micrometers to millimeters. Most honeycombs are closed cell structures. To create a honeycomb structure, these unit cells are usually repeated in two dimensions. Another important characteristic of honeycomb structures is the relative density, which is the ratio between the density of the cellular structure and that of the solid [22].

In the current study, a composite filament fabrication 3D printer was used in order to investigate the mechanical behavior of a composite structure in a honeycomb configuration. The specimens were tested in three-point bending and examined with SEM; the prediction of their deformation behavior was achieved by studying the structures using finite element analysis. The validation of the finite element model was performed using a nylon 3D printed honeycomb configuration. In this article, the possibility of creating a strong fiber reinforced honeycomb core is studied.

\section{Materials and Methods}

\subsection{Manufacturing Process Using Continuous Fiber Fabrication}

A Continuous Fiber Fabrication (CFF) 3D printer (Markforged Mark Two ${ }^{\mathrm{TM}}$, MarkForged, Somerville, MA, USA) was used for the fabrication of the honeycomb structures. The geometry of the test specimens was created using a Computer Aided Design (CAD) software package (SolidWorks ${ }^{\mathrm{TM}}$, Dassault Systems, Waltham, MA, USA). The geometry was exported as a stereolithography file (STL) and loaded into a 3D printer slicing software package (Eiger ${ }^{\mathrm{TM}}$, MarkForged, Somerville, MA, USA). All the specimens were 3D printed with a nylon filament (Nylon, MarkForged, Somerville, MA, USA) with glass fiber reinforcement (Glass Reinforcement, MarkForged, Somerville, MA, USA). Two infill strategies are available in the specific continuous fiber fabrication 3D printers utilized, as illustrated in Figure 1. The first is the Concentric fill, which simply traces a specific number of shells within the walls of the designed part. This fiber-filling approach prevents bending around the $Z$ axis and essentially reinforces the walls of the part, preventing the walls from deforming. The second reinforcement option is the Isotropic Fiber fill pattern. This pattern effectively creates a unidirectional 'sheet' of fiber on each applied layer by routing all the fibers parallel to each other in a single angular orientation, with 180 degree turns when the path reaches the edge of the part. The Isotropic Fiber fill pattern reinforces bending in the $\mathrm{XY}$ plane because any bending forces applied in that plane will generate a tensile load on at least some of the fibers, which are strongest in tension. 
Isotropic Reinforcement with $0^{\circ}$ orientation

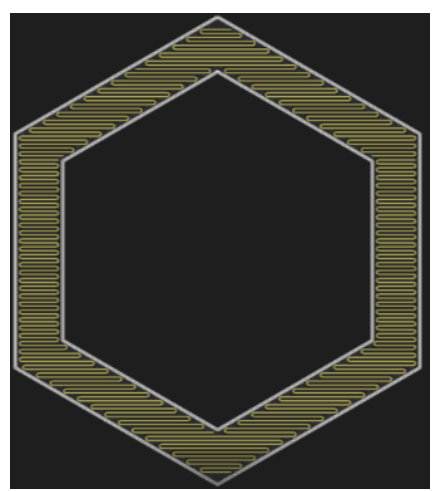

(a)

Concentric reinforcement to all walls (two Walls)

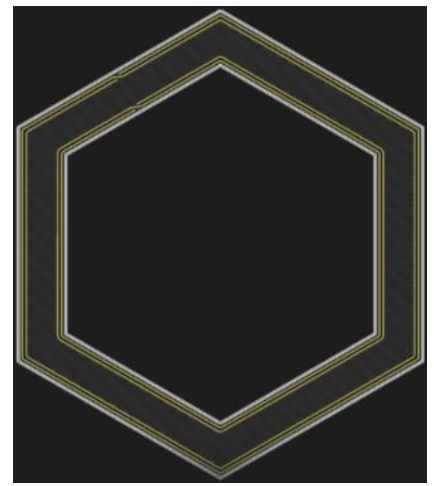

(d)

Isotropic with $0^{\circ}$ orientation and on concentric wall

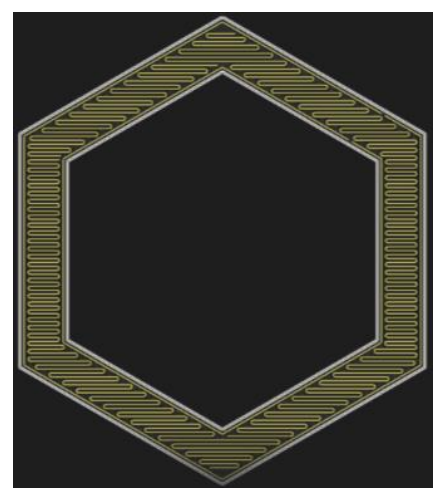

(g)
Isotropic Reinforcement with $45^{\circ}$ orientation

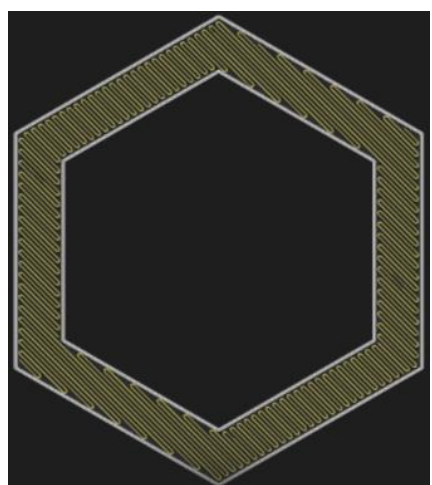

(b)

Concentric reinforcement to outer walls (two walls)

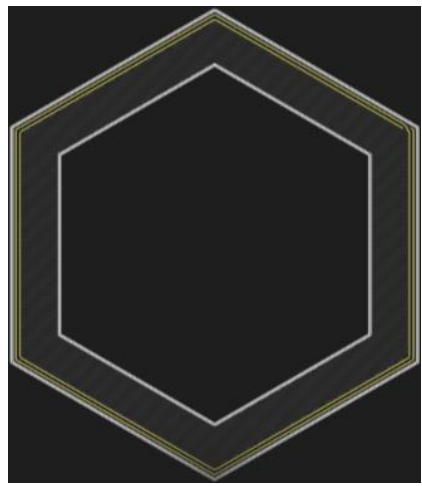

(e)

Isotropic with $45^{\circ}$ orientation and two concentric walls

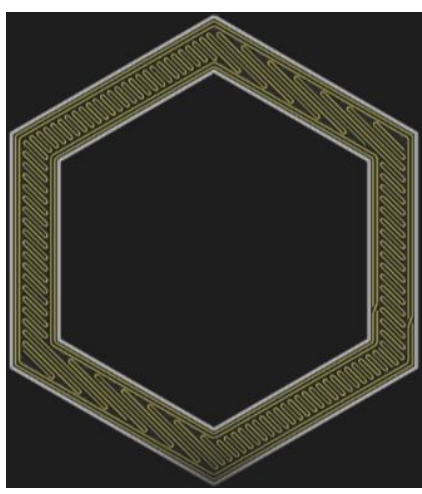

(h)
Isotropic Reinforcement with $90^{\circ}$ orientation

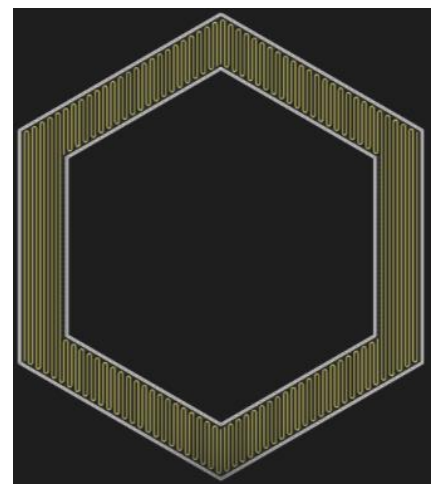

(c)

Concentric reinforcement to inner walls (two walls)

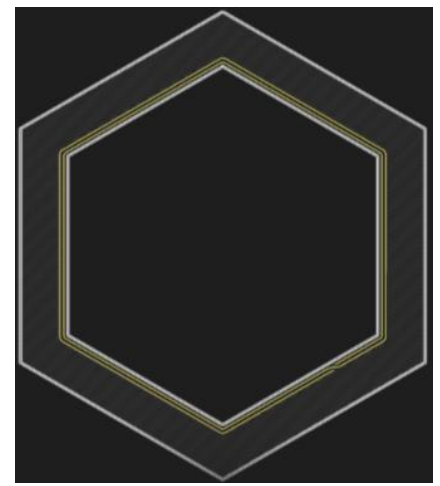

(f)

Isotropic with $90^{\circ}$ orientation and three concentric walls

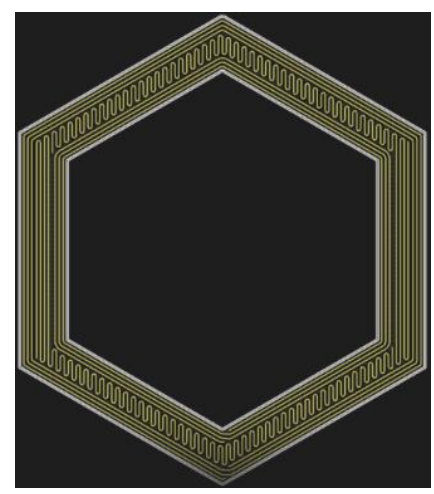

(i)

Figure 1. Isotropic reinforcement with (a) $0^{\circ}$ orientation, with (b) $45^{\circ}$ orientation and (c) $90^{\circ}$ orientation, (d) concentric fiber reinforcement for all walls, (e) for outer walls and (f) for inner walls. (g) Isotropic fill reinforcement with $0^{\circ}$, (h) $45^{\circ}$ and (i) $90^{\circ}$ with one, two and three concentric walls, respectively.

One important aspect that should be noted is that isotropic fiber, by default, puts two concentric rings of fiber around the outside of the part. This choice ensures a smoothly 
reinforced external surface as the outermost fibers are parallel and continuous to the edge of the part.

Therefore, the shape and the size of all the specimens are affected significantly from the composite filament capabilities. The importance of the width as a designed feature in 3D printed honeycombs has been shown elsewhere [25]. Another very important feature in the current study is the thickness of the honeycomb's walls. The decision to choose concentric reinforcement was also made, since it makes it possible to study continuous fiberreinforced honeycombs with relatively thin widths. Furthermore, at least two concentric glass fiber rings around each honeycomb were used with this approach. This helped to avoid problems that may have been caused by using only one concentric fiberglass ring. By taking into account all the above details and by studying how the printer operates, the decision to create honeycombs with a wall thickness of $6.5 \mathrm{~mm}$ was made. Figure 2 presents the designed honeycomb structure that was $3 \mathrm{D}$ printed and investigated mechanically with bending tests and FEA. As shown in Figure 2a the total dimensions of the structure were $126 \mathrm{~mm} \times 122 \mathrm{~mm}$ with a $5 \mathrm{~mm}$ thickness. Figure $2 \mathrm{~b}$ shows the above honeycomb structure, represented in Eiger ${ }^{\mathrm{TM}}$ software. The walls with concentric continuous glass fiber reinforcement are easily observed. It should be noted that the proposed honeycomb structure could be only a part of a larger one, as shown in Figure 2c. However, currently there are important restrictions both in size and time needed in order to print a very large structure using the continuous fiber fabrication method.

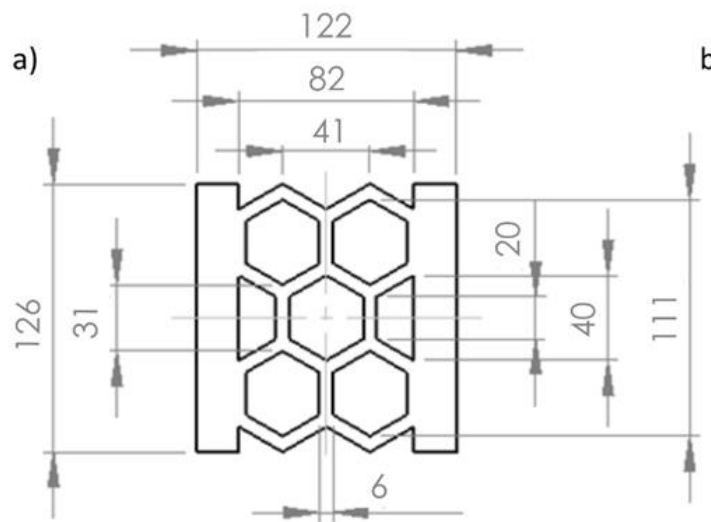

c)
)

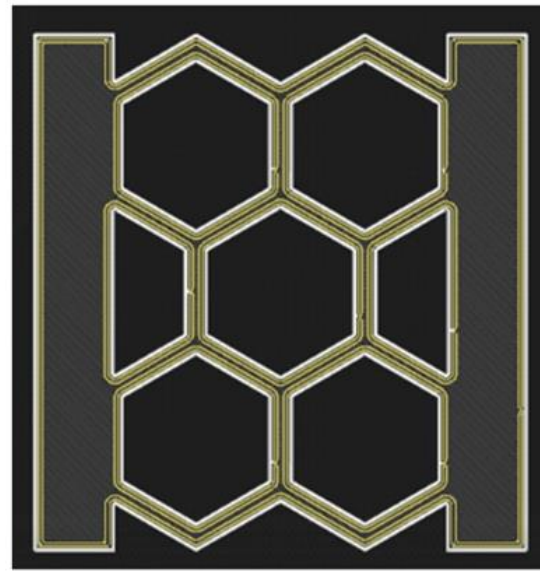

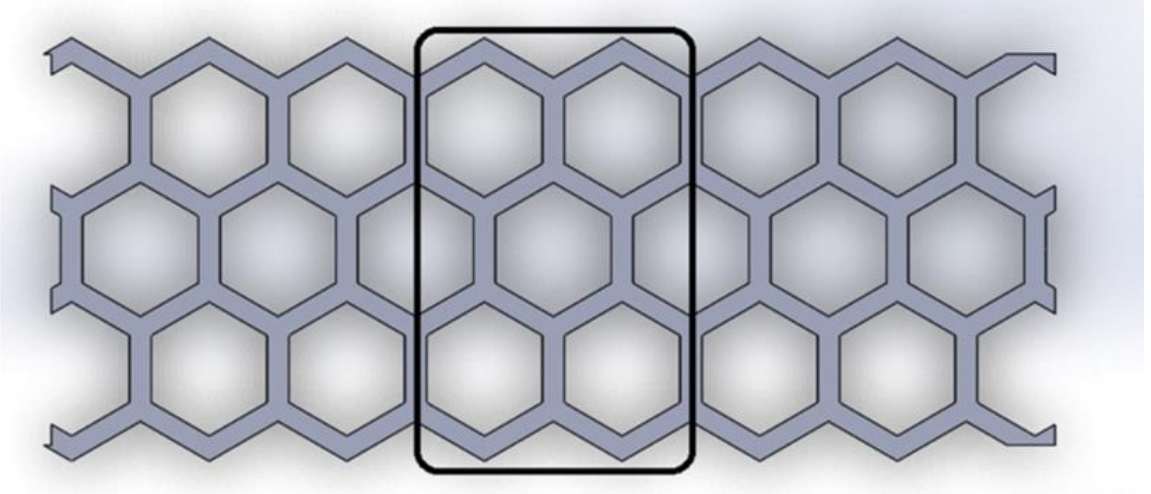

Figure 2. (a) Technical drawing of the designed honeycomb structure as specimen; (b) honeycomb structure in Eiger ${ }^{\mathrm{TM}}$ Software, by Markforged; and (c) extended honeycomb structure.

A further important detail is the minimum thickness of the 3D printed fiber. This thickness is $0.1 \mathrm{~mm}$ for fiberglass. As well as the pure nylon specimens, two different positions of the reinforcement along the build axis were applied. The layer height was selected as $0.1 \mathrm{~mm}$ and there were 50 layers in total. The positioning of the reinforcement is shown in Figure 3a,b using Eiger ${ }^{\mathrm{TM}}$ software. In the first case, nylon/FG 2-4, the sequence 
was 10 layers of nylon - 10 layers of fiberglass -10 layers of nylon -10 layers of fiberglass -10 layers of nylon (30 layers of nylon and 20 of Fiberglass). Thus, the thickness of the structure was divided into 5 parts $(5 \times 1 \mathrm{~mm})$ and the fiberglass reinforcement was added in positions 2 and 4 . In the second case, reinforcement with Nylon/FG Central, the sequence was 15 layers of Nylon -20 layers of fiberglass - 15 layers of Nylon, where again the total was 30 layers of Nylon and 20 of Fiberglass. In this case, the thickness of the structure was divided into 3 parts and the 20 layers of the fiberglass reinforcement were located centrally. A 3D printed fiberglass-reinforced sample is shown in Figure 4. The photographs were taken during the $3 \mathrm{D}$ printing process.

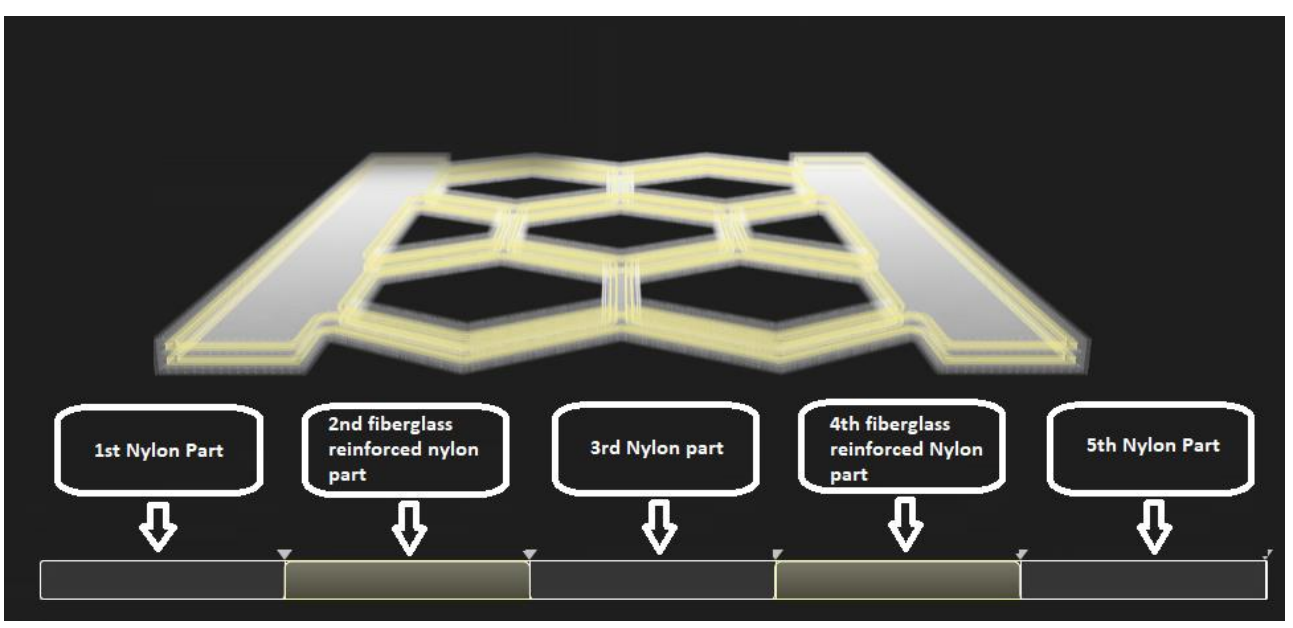

(a)

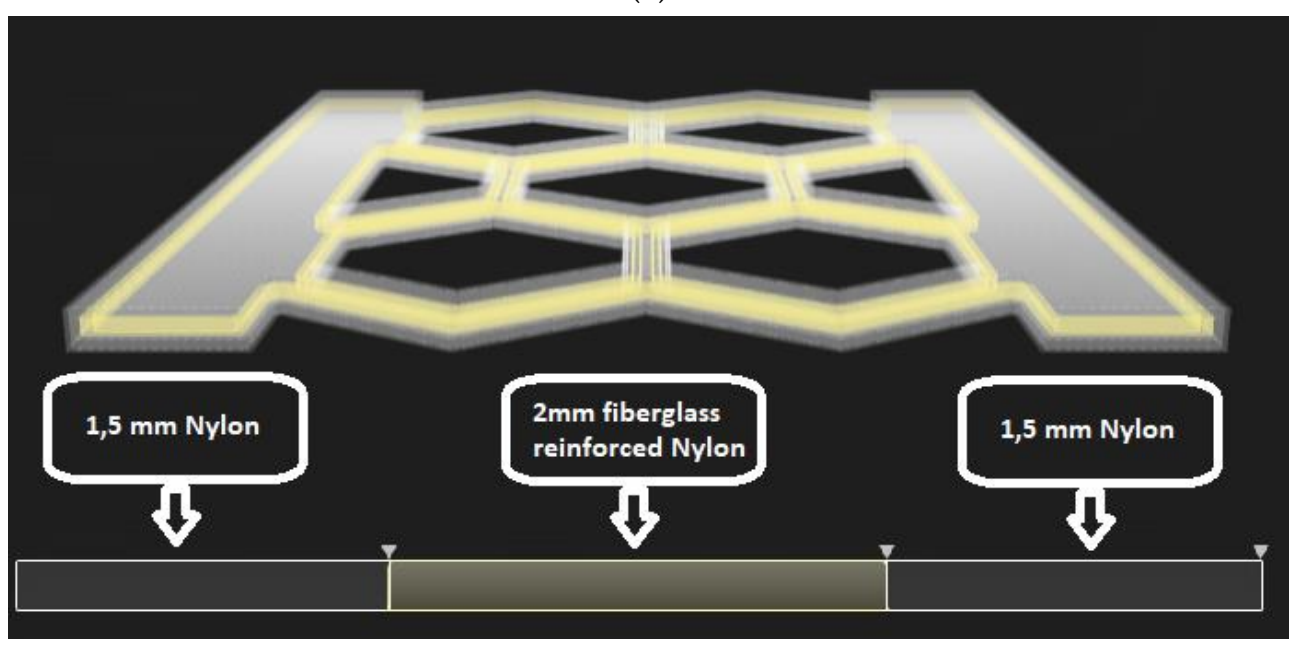

(b)

Figure 3. (a) 3D view of the fiberglass reinforced honeycomb structure (reinforcement in positions 2-4), (b) central fiberglass-reinforced honeycomb structure. 


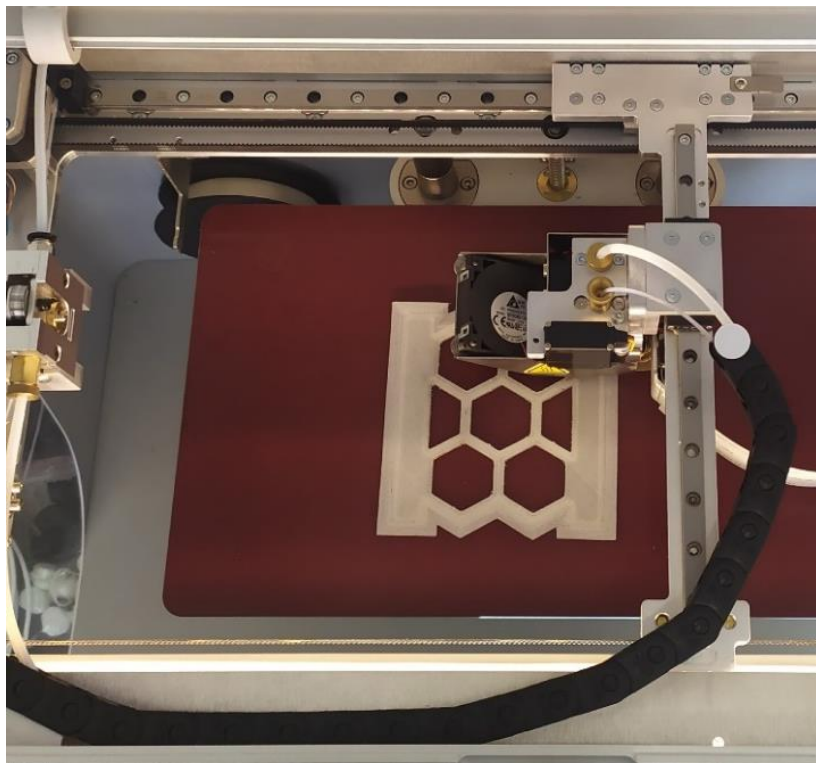

(a)

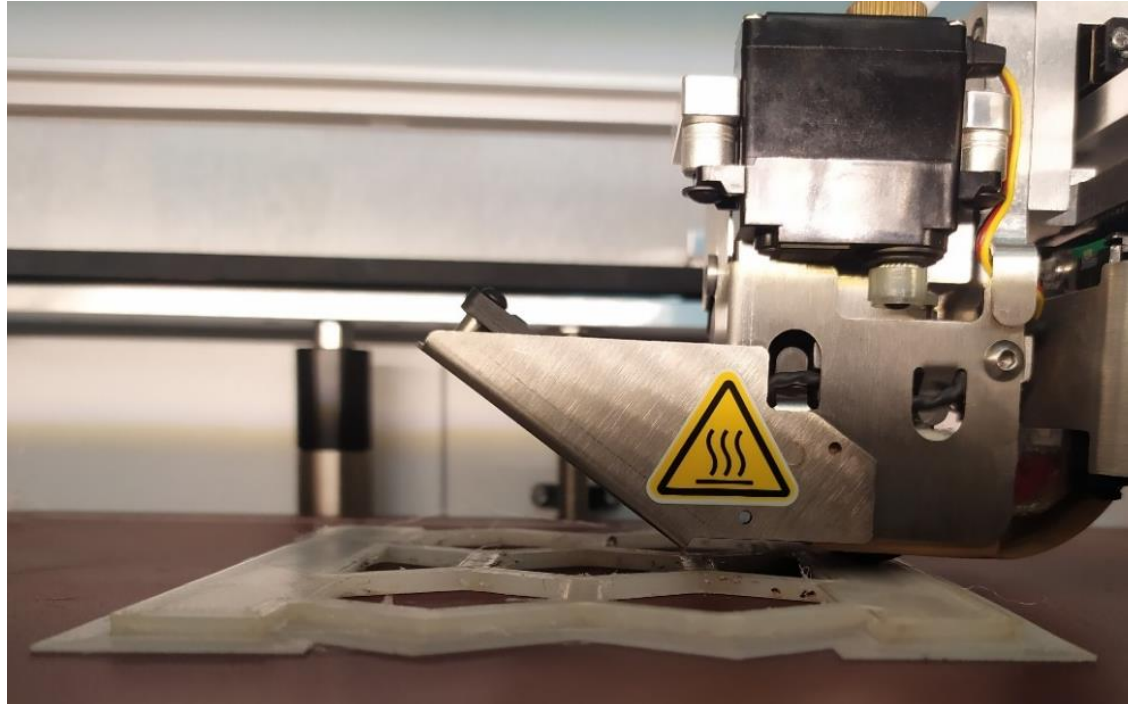

(b)

Figure 4. (a) Top and (b) side views of the 3D printing process of the fiberglass-reinforced honeycomb structure.

\subsection{FEM of Continuous Fiber-Reinforced Cellular Structures}

Currently, little information can be found in previous research concerning 3D printed cellular structures reinforced with continuous fibers, since the majority of these studies focus on reinforcement with short, randomly dispersed fibers [26,27]. A more detailed illustration of the assembly of a nylon/fiberglass reinforced honeycomb structure was imported in ANSYS and it is presented in Figure 5a. Both the nylon and the fiberglass parts are discrete. In order to ensure the mesh-independent response, a convergence study was performed. Based on the convergence results performed for the elastoplastic response of the honeycomb structures, an average element size of $1.0 \mathrm{~mm}$ was considered to be adequate to obtain acceptable accuracy in the calculated responses, as shown in Figure $5 \mathrm{~b}$. In the current FE analyses, up to 158,497 nodes and 22,048 elements were used for the generated mesh. The boundary conditions are illustrated in Figure 5c. They were considered to be simply supported, while the force was applied on the surface of the middle pin. The contact between the 3D printed specimen and the support pin was considered frictional. 


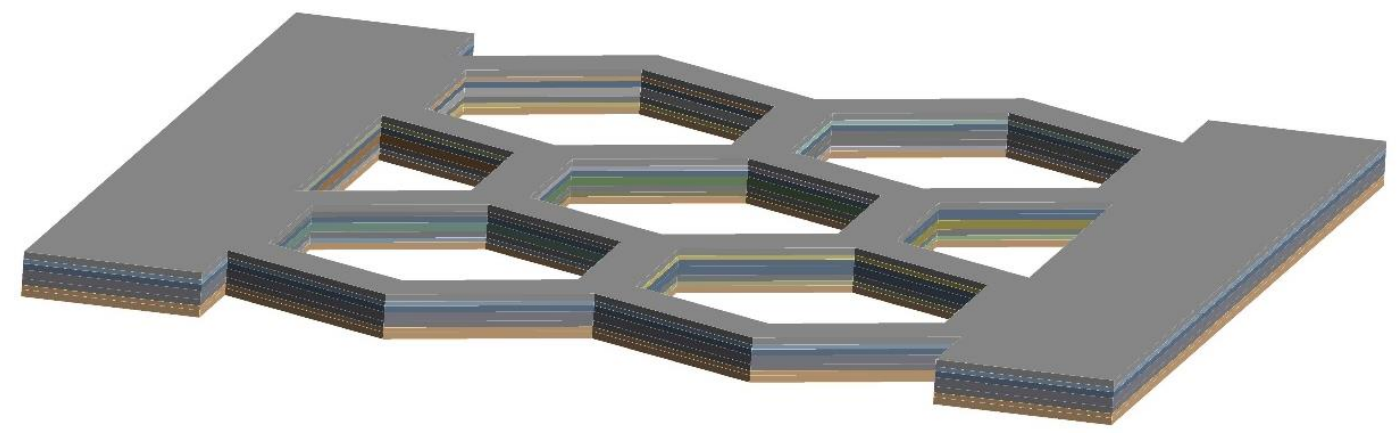

(a)

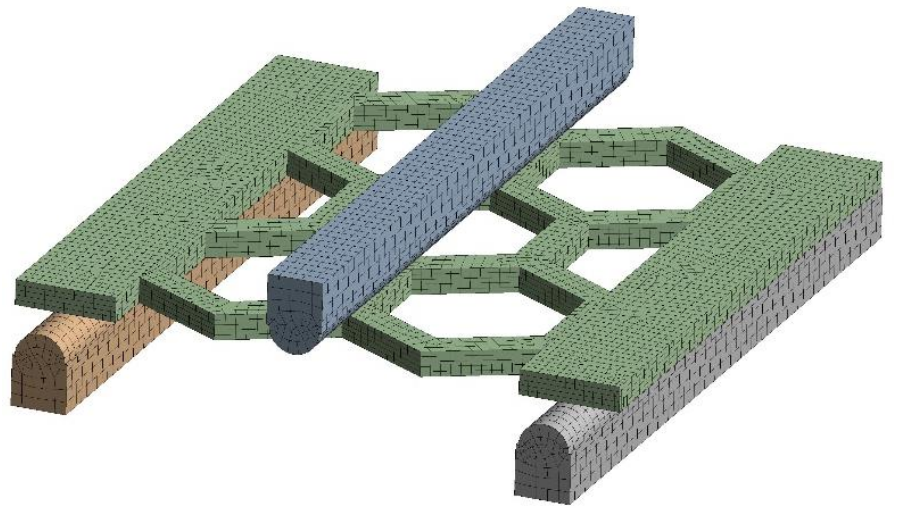

(b)

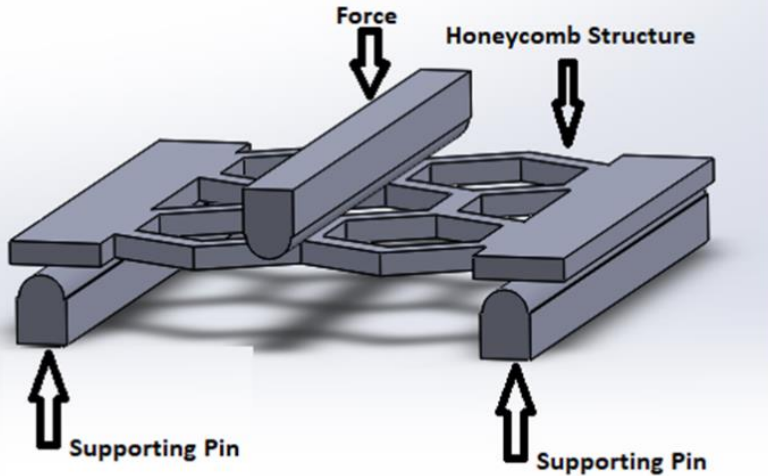

(c)

Figure 5. (a) Geometry of nylon honeycomb structure reinforced with fiberglass, (b) the corresponding mesh in ANSYS and (c) nylon honeycomb structure at three-point bending test.

It should be noted that the Finite Element Analysis (FEA) for these structures focused on the elastoplastic region of the stress-strain diagram by utilizing a multilinear kinematic hardening model. This procedure is repeated until the last pair of force depth values has converged and the loop ends. In this study, a total of 40 steps of simulation was considered adequate to fit the curve of the force displacement data from the bending tests.

\subsection{Microstructure Analysis}

The fracture surfaces of the CFF 3D printed specimens were characterized with a Scanning Electron Microscope (Phenom ProX, ThermoFisher Scientific, Waltham, MA, USA) coupled with an energy dispersive X-ray spectroscopy (EDX). The images were acquired from the cross-section area of the 3D printed specimens. The samples were mounted onto double adhesive conductive carbon tabs (TED Pella, Redding, CA, USA) on an aluminum stub (placed in a charge reduction holder) without coating and scanned at an accelerating voltage of $10 \mathrm{kV}$.

\subsection{Nanoindentation Tests}

Instrumented indentation tests were performed in order to define the material parameters of nylon and fiberglass of the honeycomb structures and utilize them in a Finite Element Model. Nanoindentation tests implicate the contact of an indenter with a material's surface and its penetration to a predetermined depth or load. The indentation force is measured along with the penetration depth.

The nanoindentation tests were performed on a DUH-211S Shimadzu (Kyoto, Japan) device, with a load resolution of $0.196 \mu \mathrm{N}$. The indenter was a Berkovich diamond tip (the tip shape is a three-sided pyramid, with a triangular projected geometry and an included angle of $65^{\circ}$; the tip radius is $100 \mathrm{~nm}$ ). Several points were selected using an optical 
microscope integrated into the indenter and these were distributed on the surface of the samples. At least ten measurements were performed per sample. The modulus and the hardness of the coatings were determined based on the work of Oliver and Pharr [28]. The indentation hardness can be determined as a function of the maximum penetration depth [29-32]. The hardness can be calculated as a function of the maximum penetration depth of the indentation:

$$
H=\frac{P_{\max }}{A}
$$

where $P_{\max }$ is the maximum applied load measured at the maximum depth of penetration $\left(h_{\max }\right)$ and $A$ is the projected contact area between the indenter and the film. For a perfect Berkovich indenter, $A$ can be expressed as a function of the contact indentation depth $h_{f}$ as:

$$
A=3 \sqrt{3} h_{f}^{2} \tan ^{2} 65^{\circ}=23.96 h_{f}^{2}
$$

The contact indentation, $h_{f}, \mathrm{n}$ be determined from the following expression:

$$
h_{f}=h_{\max }-\varepsilon \frac{P_{\max }}{S}
$$

where $\varepsilon$ is a geometric constant $\varepsilon=0.75$ for a pyramidal indenter and $S$ is the contact stiffness that can be determined as the slope of the unloading curve at the maximum loading point, i.e.,

$$
S=\left(\frac{d P}{d h}\right)_{h=h_{\max }}
$$

The reduced elastic modulus $E_{r}$ is given by:

$$
E_{r}=\frac{S}{2 \beta} \sqrt{\frac{\pi}{A}}
$$

where $\beta$ is a constant that depends on the geometry of the indenter. For the applied Berkovich indenter, the parameter $\beta$ was equal to 1.034. The specimen's elastic modulus $\left(E_{s}\right)$ can then be calculated as:

$$
\frac{1}{E_{r}}=\frac{1-v_{s}^{2}}{E_{S}}+\frac{1-v_{i}^{2}}{E_{i}}
$$

where $E_{i, s}$ and $v_{i, s}$ are the elastic modulus and the Poisson's ratio for the indenter and the specimen, respectively. Moreover, for a diamond indenter, $E_{i}$ is $1140 \mathrm{GPa}$ and $v_{i}$ is 0.07 . The specimen's hardness $H$ and elastic modulus $E_{s}$ were computed from the set of equations documented above.

\subsection{Flexural Tests}

The honeycomb structures were subjected to three-point bending tests using a universal Testometric M500-50AT (Testometric Company, Rochdale, UK) testing machine equipped with $50 \mathrm{kN}$ load cell, according to ASTM D590. The experimental setup is shown in Figure 5c. The support span was set to $128 \mathrm{~mm}$. At least three specimens were prepared and tested for each sample type; Nylon, Nylon/FG Central and Nylon/FG 2-4. The loading and supports noses featured a diameter of $10 \mathrm{~mm}$. The crosshead speed was set to $5 \mathrm{~mm} / \mathrm{min}$.

\section{Results and Discussion}

\subsection{Material Characterization of Nylon- and Fiberglass-Reinforced Cellular Structures}

Figure 6 shows SEM images at different magnifications of the fracture surfaces from the samples manufactured by the CFF 3D printing technique. To qualitatively determine the extent of the porosity within the glass fiber-reinforced composites, their cross-sections 
were examined using SEM. The void inclusions were concentrated within and around the glass fiber bundles as illustrated in Figure 6a. A weak bond between the glass fibers and the nylon matrix was observed, indicating that the fibers were not consistently bonded to the matrix. This poor bonding was more profound in the glass filament, which featured high levels of porosity compared to the 3D prints. Indeed, as illustrated in Figure $6 \mathrm{~b}$, the porosity in the printed specimens was reduced compared to the glass fiber filament. This is likely to have contributed to the expected good structural integrity and strength of the samples. Similar observations were observed elsewhere [33].

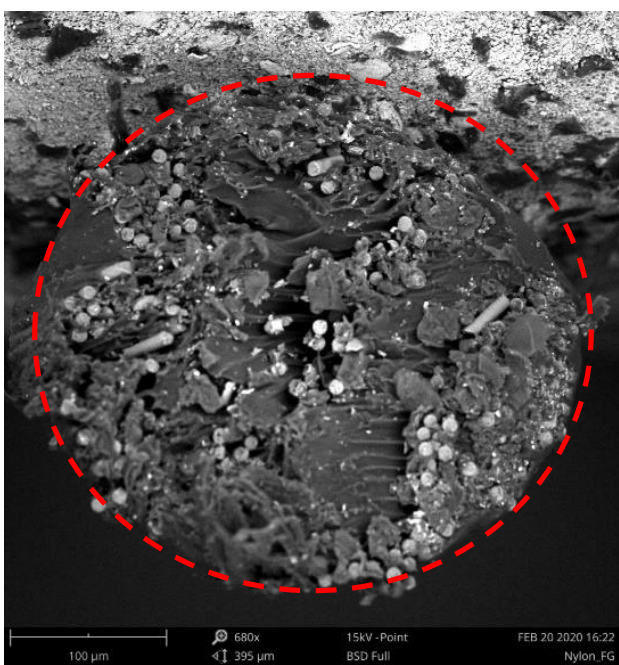

(a)

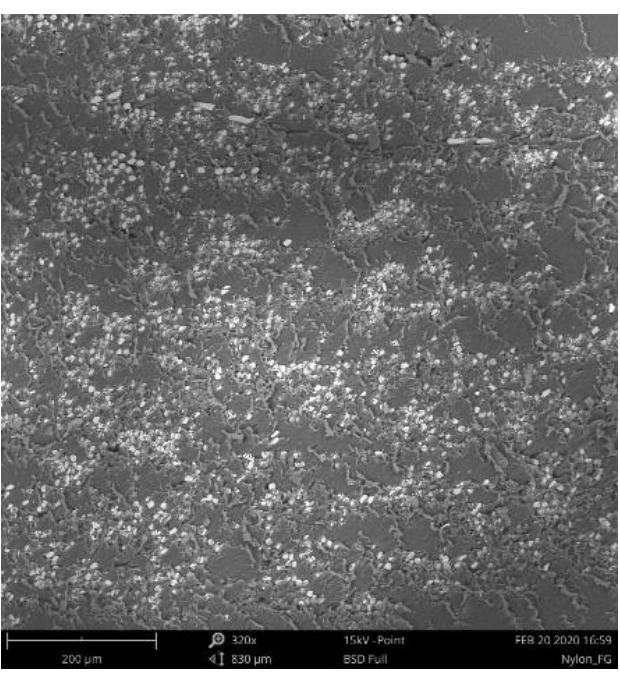

(b)

Figure 6. SEM microstructure of the cross section of nylon and nylon/fiberglass showing that (a) the glass filament (within the red dotted circle) contained empty space around fiber bundles and (b) the 3D printed specimen contained no extensive visible porosity.

Additionally, the EDX analysis, shown in Figure 7, revealed an inhomogeneous dispersion of fibers, as revealed from the detection of silicon in the X-ray elemental maps. The top part of the images shows the neat Nylon matrix, since no silicon was detected in this area. 

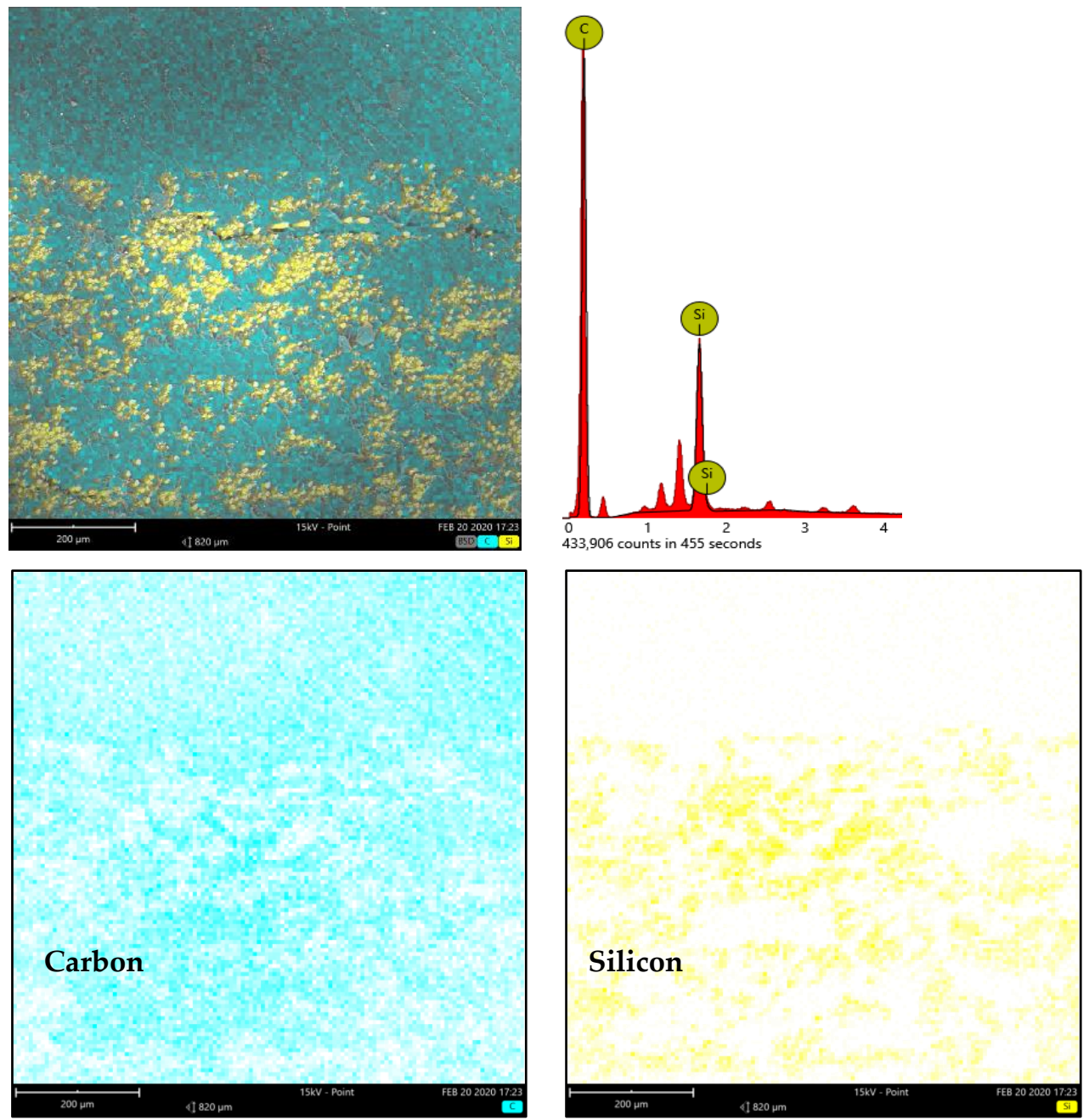

Figure 7. Energy dispersive X-ray (EDX) mapping analysis of 3D printed specimens showing layers with and without the presence of glass fibers.

Following the morphological analysis, the mechanical behavior of the neat nylon and nylon/fiberglass specimens was examined using nanoindentation testing. In Figure 8a, the load-depth curves are illustrated for the neat nylon and nylon/fiberglass specimens, as measured on the nanoindentation tests. The maximum indentation depth exhibited an average value of $3.7 \pm 0.4 \mu \mathrm{m}$ for the nylon specimens. The maximum indentation depths were between approximately 1.9 to $3.9 \mu \mathrm{m}$ for Nylon/Fiberglass specimens. This can be attributed to the fact that the indenter was applied on the nylon and nylon/fiberglass parts, as the measurements were scattered on the surface of the sample, as illustrated in Figure 8c. The average elastic modulus for the nylon specimens was $1069 \mathrm{MPa}$. The modulus for the nylon/fiberglass specimens varied on the nanoindentation point, returning values between $1210 \mathrm{MPa}$ and $7352 \mathrm{MPa}$. 


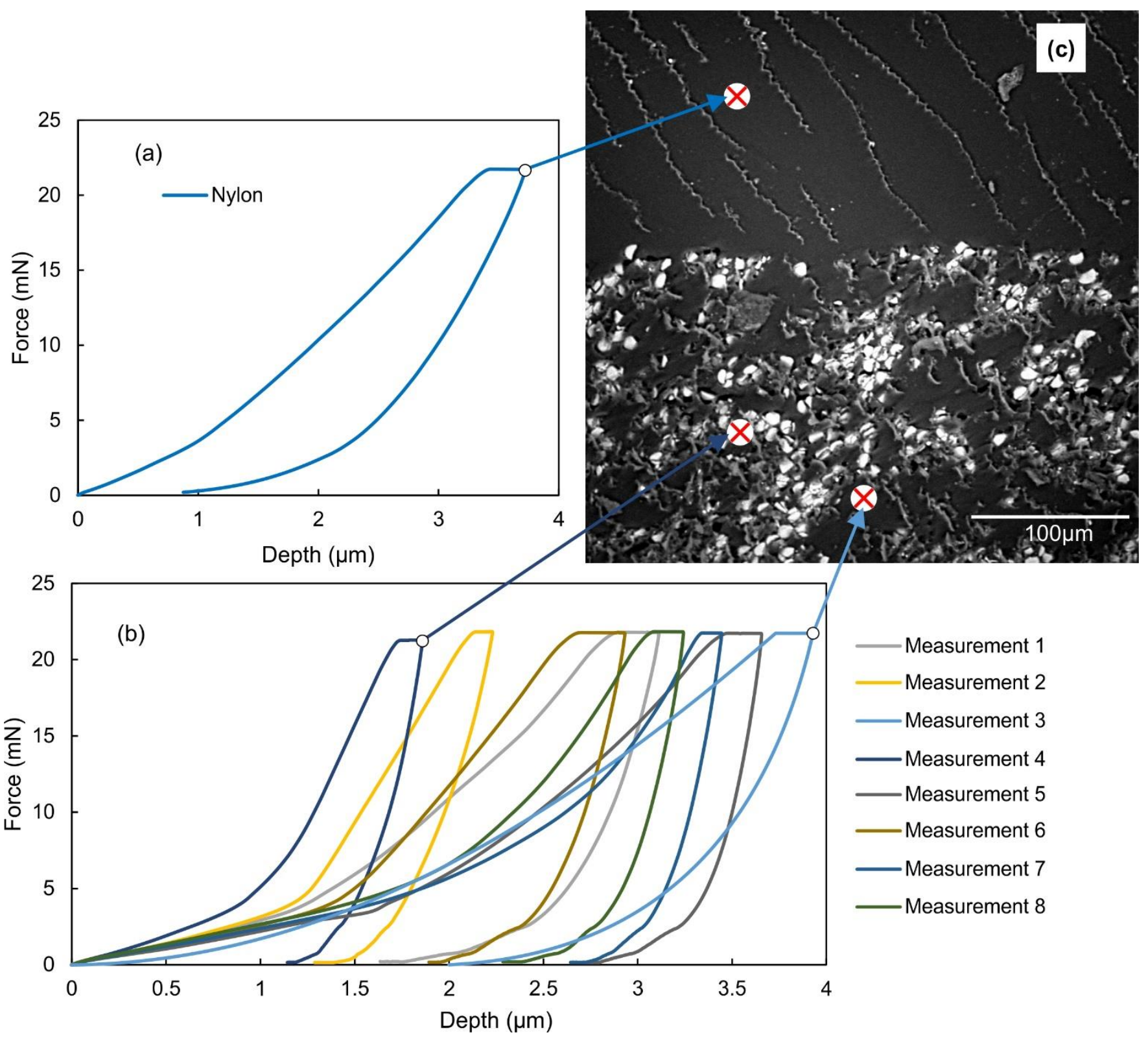

Figure 8. Comparison of typical load depth nanoindentation curves of (a) nylon and (b) nylon/Fiberglass, while (c) represents SEM of the scattered nanoindentation points on the cross section of nylon/Fiberglass specimens.

\subsection{Experimental and FEA Bending Behavior of Nylon- and Fiberglass-Reinforced Cellular Structures}

In this section, nanoindentation, flexural, and FEM-extracted stress-strain properties of the added manufactured nylon and glass fiber-reinforced nylon cellular structures are presented. Three specimens were tested per material for each type of test. It should be noted that the volume fraction of the glass fiber is $12 \mathrm{vol} \%$.

Although there is much relevant research available on nylon and fiberglass, properties such as the elasticity modulus and the density of the materials that were utilized in the FEM were measured in detail. The elasticity modulus was calculated through the Oliver-Pharr method from the nanoindentation curves, where the highest values were utilized in the FE analysis. It is important to emphasize that due to the imperfections that 3D printed technology may cause in the structure (gaps in the main body of the build item), the theoretical density of the material is not the same for the 3D printed construct. This phenomenon may cause significant problems, since high-precision details should be 
available in order to build a reliable FEA model. The method that was used in order to find the accurate density of the material was to print the structure and then obtain its volume accurately using the SolidWorks model. By weighting the 3D printed structure (calculating the mass) and dividing the mass by the volume, the actual density was determined.

It should be noted that multilinear isotropic hardening models were used in order to obtain a more precise plastic deformation of the honeycomb structures. The important property of multilinear isotropic hardening is the fact that the yield surface expands uniformly in all directions with plastic flow [34].

Three-point bending tests were performed for all the 3D printed cellular structures and the typical force-deflection behavior is illustrated in Figure 9. It can be observed that the maximum force that was applied on the nylon structures was $181.4 \mathrm{~N}$. The addition of fiberglass increased the ultimate forces to $296.3 \mathrm{~N}$ and $442.1 \mathrm{~N}$ for the central fiberglassreinforced and fiberglass-reinforced composites in positions $2-4$, respectively. Figure 10a- $d$ show the SEM images at different magnifications of the fracture surfaces of the samples manufactured by the CFF 3D printing technique. Small interlaminar cracks appeared within the $3 \mathrm{D}$ printed layers as well as on the interface of the glass fiber when subjected to bending loads, which was attributed to poor bonding of the fibers with the nylon matrix. At higher magnifications, this is illustrated more clearly as the fibers appear to feature negligible bonding on their perimeter with the nylon matrix.

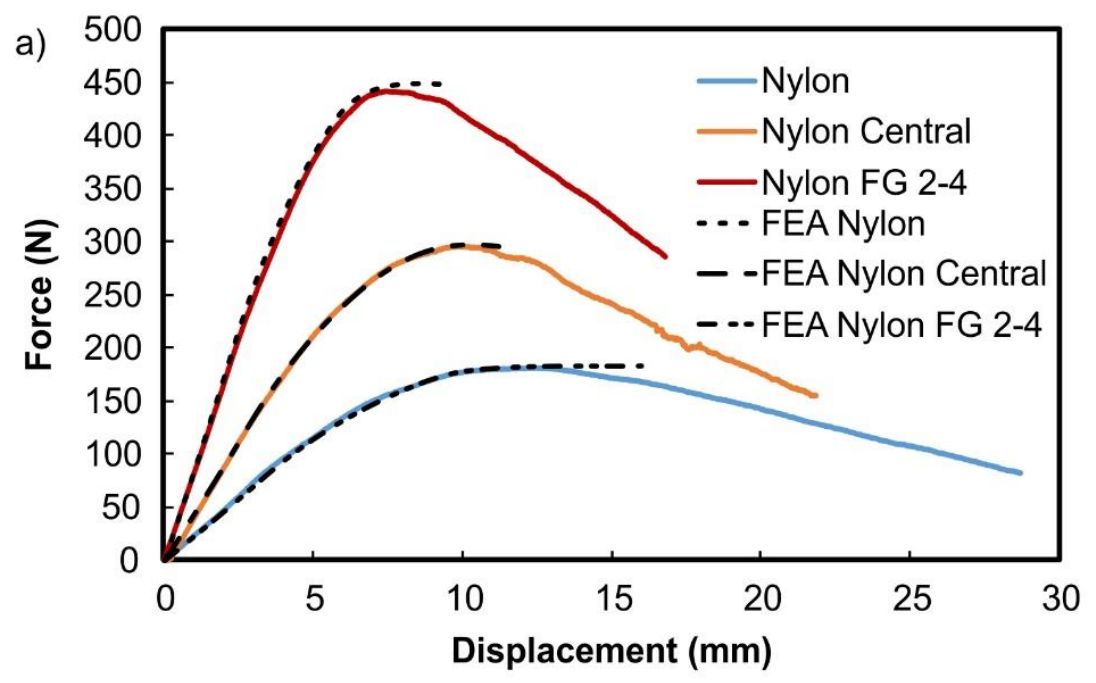

b)

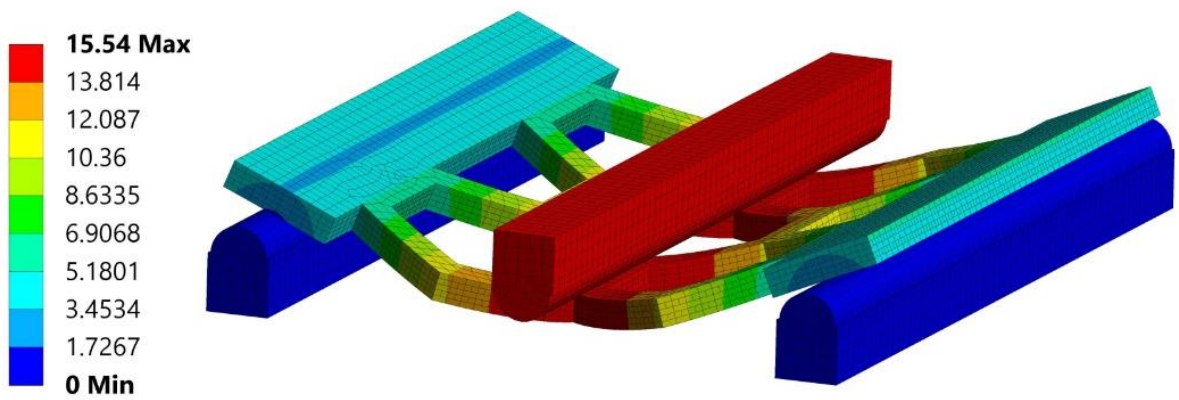

Figure 9. (a) Force-deflection curves of experimental and FEA for Nylon, Nylon FG central and Nylon FG, top 2-4 positions; and (b) typical deformation ( $\mathrm{mm}$ ) response of the FE model under three-point bending. 


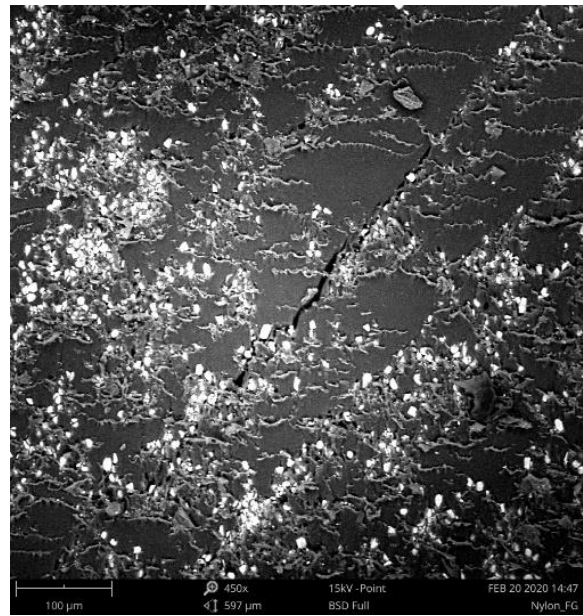

(a)

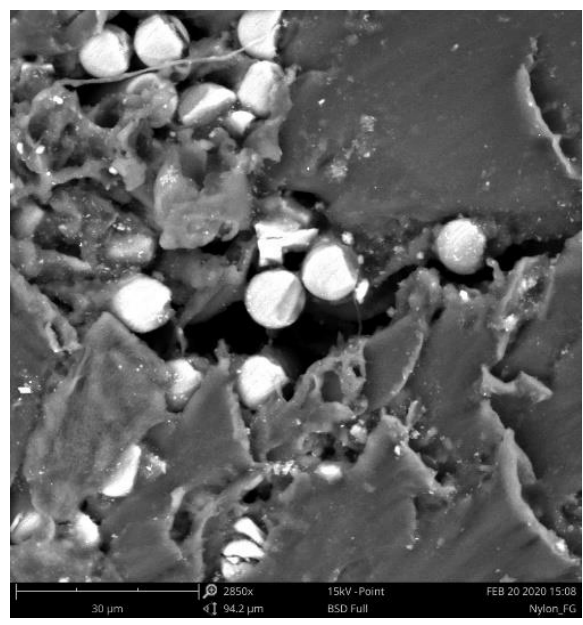

(c)

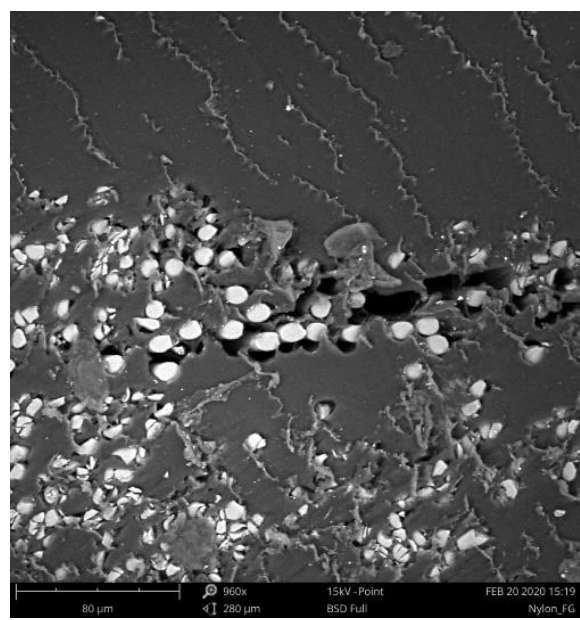

(b)

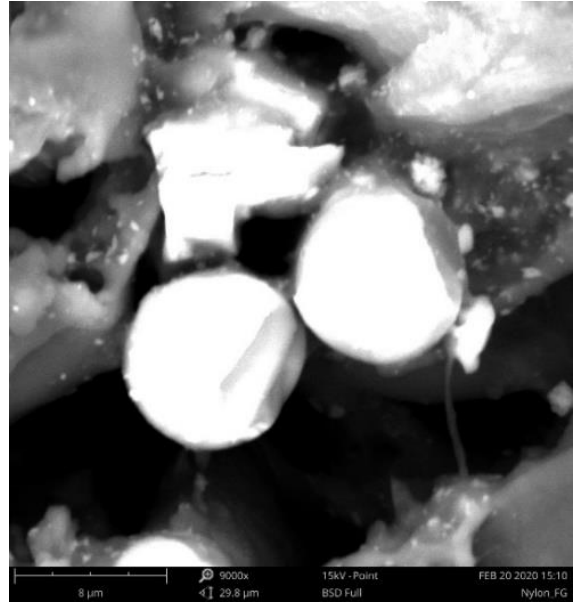

(d)

Figure 10. SEM images of the glass fiber distribution at different magnifications showing (a) interlaminar crack propagation between the 3D printed layers, (b) crack propagation on the interface of glass fibers and nylon matrix, (c) debonded glass fibers from the nylon matrix and (d) high magnification of the interfacially debonded fibers.

In order to validate the FEA model, the FEA results were compared with the experimental flexural tests. Figure $9 \mathrm{a}$ also presents the level of convergence between the experimental and the FEA results. From Figure $9 a$, the results are very encouraging as for the same experimental deflections, the respective ultimate forces were at $181.4 \mathrm{~N}, 296.3 \mathrm{~N}$ and $442.1 \mathrm{~N}$ for the nylon, central fiberglass-reinforced and fiberglass-reinforced fibers in positions $2-4$, respectively. In addition, it is evident that for the fiberglass-reinforced specimens, the results from the experiments and the FEA were very close. On the other hand, the results (FEA and experimental) for the nylon specimen seemed to suggest a slightly larger deviation. This phenomenon may have occurred due to the fact that the proposed methodology of simulating 3D printed fiber-reinforced specimens can make it possible to simulate the behavior of these specimens in great detail by dividing them into separate parts and considering them perfectly bonded in ANSYS. To sum up, from Figure 9, there is strong evidence that the Finite Element Analysis Model is able to offer reliable results, as the pairs of force-deflection that were recorded both in the experiment and in the simulation were very close to each other.

Figure 11 illustrates the FEM-determined stress-strain behavior of the Nylon, Nylon FG central, and Nylon FG 2-4 positions, in which higher yielding was observed for the Nylon FG's top 2-4 positions. Considering these results, it can be concluded that the 
glass fibers significantly affected the honeycomb's mechanical properties and their overall stress-strain behavior. Furthermore, the position of the glass fibers in the nylon honeycomb structure also improved the stress-strain behavior when compared with the reference the nylon structure. The maximum flexural stress (ultimate) of the nylon structures was calculated to be $45.56 \mathrm{MPa}$. Considering the reinforced structures, the ultimate flexural stress of Nylon FG central and Nylon FG 2-4 was calculated at 73.50 MPa and 109.67 MPa, respectively. All these details are presented graphically in Figure 11. All the above information were obtained by taking into consideration that the initial slope is where stress is directly proportional to strain. The yield point of each structure was calculated by FEA-generated stress-strain curves.

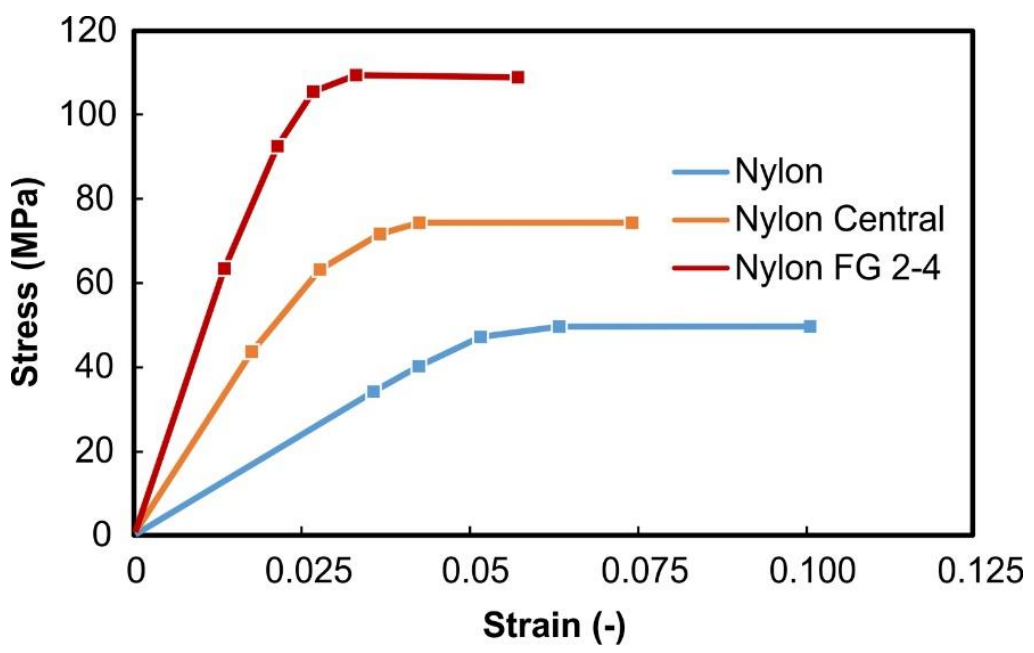

Figure 11. FEM-determined stress-strain curves of Nylon, Nylon FG central and Nylon FG, top 2-4 positions.

Considering the results from the bending tests and the FEA simulations, it is crucial to make a comparison between the different kinds of reinforcements that were studied. This analysis will set the basis for further investigation in the fields of 3D printed continuous fiber reinforcement. Figures 9 and 11 compare the nylon specimen with the two kinds of fiber reinforcements that were studied.

It is clear from Figure 12 that fiberglass reinforcement ameliorated the bending behavior of the studied honeycomb structure. In terms of the flexural strength (Figure 12a), the Nylon/GF Central specimens demonstrated a $61 \%$ increase ( $\pm 7.5 \mathrm{MPa}$ ) compared to the nylon specimens, while the Nylon/GF $2-4$ presented an increase of $141 \%$ ( $\pm 10 \mathrm{MPa})$. Considering the flexural modulus (Figure 12b), the Nylon/GF Central specimens demonstrated a $166 \%$ increase ( $\pm 200 \mathrm{MPa}$ ) compared to the nylon specimens, while the Nylon/GF $2-4$ presented an increase of $432 \%( \pm 300 \mathrm{MPa})$. The flexural stiffness is a criterion of measuring deformability. The flexural stiffness of a structure is a function based upon two essential properties: the elastic modulus, E (stress per unit strain) of the material that composes it, and the moment of inertia, I, a function of the cross-sectional geometry. The flexural stiffness in this paper is defined as the ratio between the applied force and the corresponding displacement. In terms of flexural stiffness (Figure 12c), the Nylon/GF Central specimens demonstrated an $84 \%$ increase ( $\pm 7.4 \mathrm{MPa}$ ) compared to the nylon specimens, while the Nylon/GF 2-4 presented an increase of $243 \%$ ( $\pm 9 \mathrm{MPa})$. However, it seemed that central fiberglass reinforcement presented less improvement. This was an expected observation, since it is logical to notice better bending behavior as the strong material is placed near the top and bottom bending surfaces. Finally, it is clear that FEA models provide extremely reliable results. 
a)

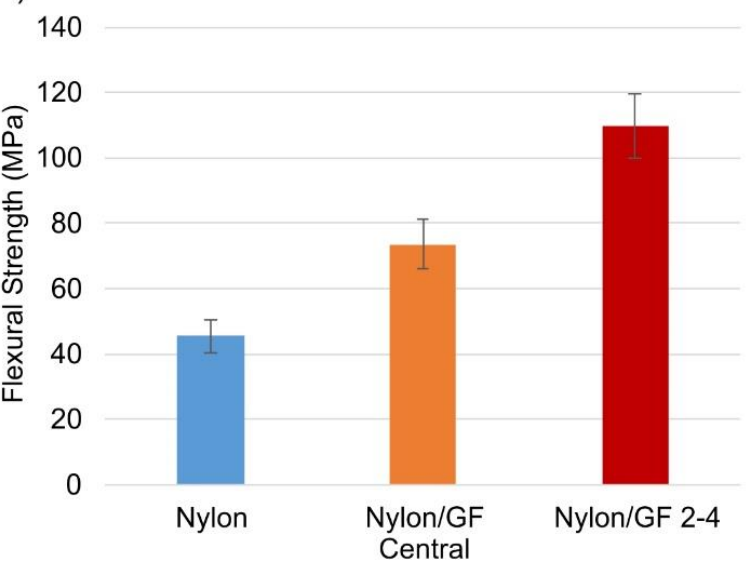

b)

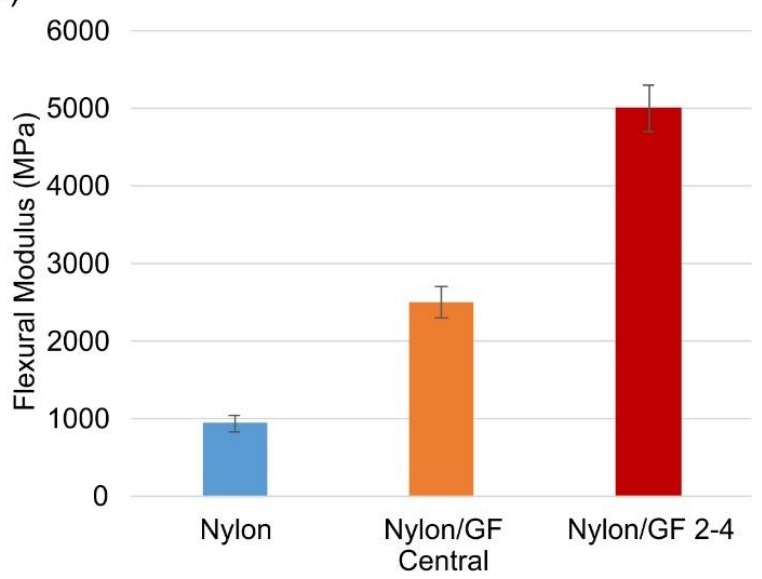

c)

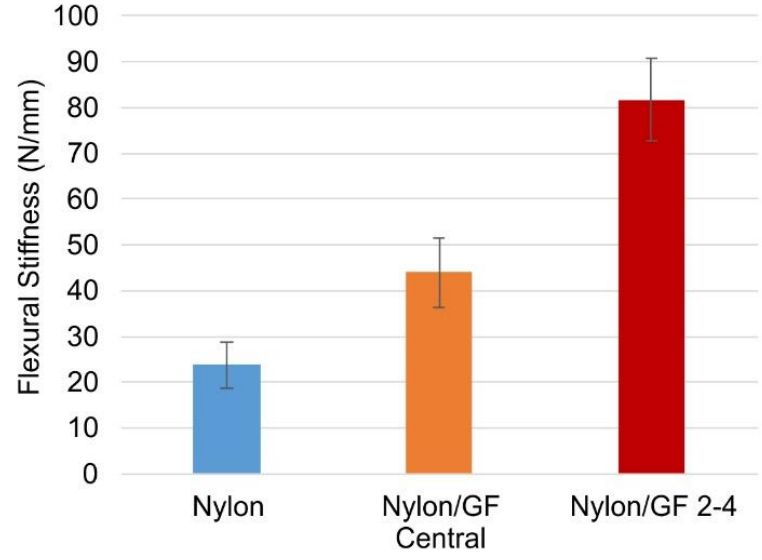

Figure 12. (a) Flexural strength, (b) flexural modulus and (c) flexural stiffness for each nylon structure reinforced with fiberglass in different positions.

\section{Conclusions}

The main objective of this paper was to study the mechanical properties of 3D printed fiber reinforced honeycomb structures. The fiber reinforcement was 3D printed inside a honeycomb structure at predetermined regions using a CFF 3D printer (Markforged Mark Two $\left.{ }^{\mathrm{TM}}\right)$. Stiff honeycomb cores were fabricated to compete with the mechanical properties of the stiff fiber panels in sandwich structures. The mechanical behavior of the composite nylon/fiberglass filaments was examined with SEM and nanoindentation testing. A Finite Element Analysis model was developed to simulate the 3D printed fiber reinforced honeycomb structures. It is evident that $3 \mathrm{D}$ printed-continuous fiberglass reinforcement significantly ameliorates the behavior of the studied honeycomb structure. The significance and potential applications of this work include the possibility of replacing lightweight honeycomb cores with stiffer (fiber-reinforced) cores, which was proven in this study to be a very promising approach.

Author Contributions: Conceptualization, E.G., K.T., E.K.T., A.K. and D.T.; methodology, K.T. and D.T.; software, E.G., K.T. and E.K.T.; validation, K.T., and D.T.; formal analysis, E.G., K.T., E.K.T. and D.T.; investigation, E.G., K.T. and D.T.; data curation, E.G., K.T. and E.K.T.; writing—original draft preparation, E.G., K.T., and D.T.; writing-review and editing, K.T., A.K. and D.T.; visualization, E.G., K.T. and E.K.T.; supervision, D.T. All authors have read and agreed to the published version of the manuscript.

Funding: This research received no external funding.

Conflicts of Interest: The authors declare no conflict of interest. 


\section{References}

1. Dickson, A.N.; Barry, J.N.; McDonnell, K.A.; Dowling, D.P. Fabrication of continuous carbon, glass and Kevlar fibre reinforced polymer composites using additive manufacturing. Addit. Manuf. 2017, 16, 146-152.

2. Liu, Z.; Wang, Y.; Wu, B.; Cui, C.; Guo, Y.; Yan, C. A critical review of fused deposition modeling 3D printing technology in manufacturing polylactic acid parts. Int. J. Adv. Manuf. Technol. 2019, 102, 2877-2889. [CrossRef]

3. Kabir, S.M.F.; Mathur, K.; Seyam, A.-F.M. The Road to Improved Fiber-Reinforced 3D Printing Technology. Technologies $2020,8,51$. [CrossRef]

4. Fidan, I.; Imeri, A.; Gupta, A.; Hasanov, S.; Nasirov, A.; Elliott, A.; Alifui-Segbaya, F.; Nanami, N. The trends and challenges of fiber reinforced additive manufacturing. Int. J. Adv. Manuf. Technol. 2019, 102, 1801-1818. [CrossRef]

5. Mansour, M.; Tsongas, K.; Tzetzis, D.; Antoniadis, A. Mechanical and dynamic behavior of fused filament fabrication 3D printed polyethylene terephthalate glycol reinforced with carbon fibers. Polym.-Plast. Technol. Eng. 2018, 57, 1715-1725. [CrossRef]

6. Mansour, M.; Tsongas, K.; Tzetzis, D. Measurement of the mechanical and dynamic properties of 3D printed polylactic acid reinforced with graphene. Polym.-Plast. Technol. Eng. 2019, 58, 1234-1244. [CrossRef]

7. Mansour, M.T.; Tsongas, K.; Tzetzis, D. 3D Printed Hierarchical Honeycombs with Carbon Fiber and Carbon Nanotube Reinforced Acrylonitrile Butadiene Styrene. J. Compos. Sci. 2021, 5, 62. [CrossRef]

8. Kim, J.; Kang, B.S. Enhancing Structural Performance of Short Fiber Reinforced Objects through Customized Tool-Path. Appl. Sci. 2020, 10, 8168. [CrossRef]

9. Sanei, S.H.R.; Popescu, D. 3D-Printed Carbon Fiber Reinforced Polymer Composites: A Systematic Review. J. Compos. Sci. 2020, 4, 98. [CrossRef]

10. Kousiatza, C.; Tzetzis, D.; Karalekas, D. In-situ characterization of 3D printed continuous fiber reinforced composites: A methodological study using fiber Bragg grating sensors. Compos. Sci. Technol. 2019, 174, 134-141. [CrossRef]

11. Mohammadizadeh, M.; Imeri, A.; Fidan, I.; Elkelany, M. 3D printed fiber reinforced polymer composites-Structural analysis. Compos. Part B Eng. 2019, 175, 107112. [CrossRef]

12. Hu, C.; Sun, Z.; Xiao, Y.; Qin, Q. Recent Patents in Additive Manufacturing of Continuous Fiber Reinforced Composites. Recent Pat. Mech. Eng. 2019, 12, 25-36. [CrossRef]

13. Pappas, J.M.; Thakur, A.R.; Leu, M.C.; Dong, X. A parametric study and characterization of additively manufactured continuous carbon fiber reinforced composites for high-speed 3D printing. Int. J. Adv. Manuf. Technol. 2021, 113, 2137-2151. [CrossRef]

14. Kabir, S.M.F.; Mathur, K.; Seyam, A.-F.M. A critical review on 3D printed continuous fiber-reinforced composites: History, mechanism, materials and properties. Compos. Struct. 2020, 232, 111476. [CrossRef]

15. Giannakis, E.; Koidis, C.; Tzetzis, D.; Kyratsis, P. Static and Fatigue Properties of 3D Printed Continuous Carbon Fiber Nylon Composites. Int. J. Modern Manuf. Technol. 2019, 11, 69-76.

16. Blok, L.G.; Longana, M.L.; Yu, H.; Woods, B.K.S. An investigation into 3D printing of fibre reinforced thermoplastic composites. Addit. Manuf. 2018, 22, 176-186. [CrossRef]

17. Melenka, G.W.; Cheung, B.K.O.; Schofield, J.S.; Dawson, M.R.; Carey, J.P. Evaluation and prediction of the tensile properties of continuous fiber-reinforced 3D printed structures. Compos. Struct. 2016, 153, 866-875. [CrossRef]

18. Li, N.; Li, Y.; Liu, S. Rapid prototyping of continuous carbon fiber reinforced polylacticacid composites by 3D printing. J. Mater. Process. Technol. 2016, 238, 218-225. [CrossRef]

19. Petrone, G.; Rao, S.; de Rosa, S.; Mace, B.R.; Franco, F.; Bhattacharyya, D. Behaviour of fibre-reinforced honeycomb core under low velocity impact loading. Compos. Struct. 2013, 100, 356-362. [CrossRef]

20. López, G.I.; Chiné, J.L.B.; León, S. FEM Modeling of a 3D Printed Carbon Fiber Pylon. In Proceedings of the COMSOL Conference, Rotterdam, The Netherlands, 18-19 October 2017.

21. Kim, H.; Park, E.; Kim, S.; Park, B.; Kim, N.; Lee, S. Experimental Study on Mechanical Properties of Single- and Dual-Material 3D Printed Products. Procedia Manuf. 2017, 10, 887-897. [CrossRef]

22. Zhang, J.; Zhou, Z.; Zhang, F.; Tan, Y.; Tu, Y.; Yang, B. Performance of 3D-Printed Continuous-Carbon-Fiber-Reinforced Plastics with Pressure. Materials 2020, 13, 471. [CrossRef]

23. Zhang, Q.; Yang, X.; Li, P.; Huang, G.; Feng, S.; Shen, C.; Han, B.; Zhang, X.; Jin, F.; Xu, F.; et al. Bioinspired engineering of honeycomb structure-Using nature to inspire human innovation. Prog. Mater. Sci. 2015, 74, 332-400. [CrossRef]

24. Lam, Q.; Patil, D.; Le, T.; Eppley, T.; Salti, Z.; Goss, D.; Grishin, A.; Bhate, D. An Examination of the Low Strain Rate Sensitivity of Additively Manufactured Polymer, Composite and Metallic Honeycomb Structures. Materials 2019, 12, 3455. [CrossRef]

25. Wang, Z.; Liu, J.; Lu, Z.; Hui, D. Mechanical behavior of composited structure filled with tandem honeycombs. Compos. Part B 2017, 114, 128-138. [CrossRef]

26. Mansour, M.T.; Tsongas, K.; Tzetzis, D.; Antoniadis, A. The in-plane compression performance of hierarchical honeycomb additive manufactured structures. In Proceedings of the IOP Conference Series: Materials Science and Engineering, University of Pitesti, Pitesti, Romania, 22-24 May 2019. [CrossRef]

27. Mansour, M.T.; Tsongas, K.; Tzetzis, D. The mechanical performance of 3D printed hierarchical honeycombs using carbon fiber and carbon nanotube reinforced acrylonitrile butadiene styrene filaments. MATEC Web of Conferences. In Proceedings of the 7th International Conference of Materials and Manufacturing Engineering (ICMMEN 2020), Thessaloniki, Greece, 2-3 July 2020. [CrossRef] 
28. Oliver, W.C.; Pharr, G.M. An Improved Technique for Determining Hardness and Elastic-Modulus using Load and Displacement Sensing Indentation Experiments. J. Mater. Res. 1992, 7, 1564-1583. [CrossRef]

29. Tzetzis, D.; Mansour, G.; Tsiafis, I.; Pavlidou, E. Nanoindentation Measurements of Fumed Silica Epoxy Reinforced Nanocomposites. J. Reinf. Plast. Compos. 2013, 32, 163-173. [CrossRef]

30. Tzetzis, D.; Tsongas, K.; Mansour, G. Determination of the Mechanical Properties of Epoxy Silica Nanocomposites through FEA-Supported Evaluation of Ball Indentation Test Results. Mater. Res. 2017, 20, 1571-1578. [CrossRef]

31. Tsongas, K.; Tzetzis, D.; Karantzalis, A.; Banias, G.; Exarchos, D.; Ahmadkhaniha, D.; Zanella, C.; Matikas, T.; Bochtis, D. Microstructural, surface topology and nanomechanical characterization of electro-deposited Ni-P/SiC nanocomposite coatings. Appl. Sci. 2019, 9, 2901. [CrossRef]

32. Mansour, G.; Zoumaki, M.; Tsongas, K.; Tzetzis, D. Microstructural and Finite Element Analysis-assisted Nanomechanical Characterization of Maize Starch Nanocomposite Films. Mater. Res. 2021, 24, e20200409. [CrossRef]

33. Ning, F.; Cong, W.; Qiu, J.; Wei, J.; Wang, S. Additive manufacturing of carbon fiber reinforced thermoplastic composites using fused deposition modeling. Compos. Part B Eng. 2015, 80, 369-378. [CrossRef]

34. Zhang, M.; Benítez, J.M.; Montáns, F.J. Cyclic plasticity using Prager's translation rule and both nonlinear kinematic and isotropic hardening: Theory, validation and algorithmic implementation. Comput. Methods Appl. Mech. Engrg. 2018, 328, 565-593. [CrossRef] 